\title{
Microphysical transition in water clouds over the Amazon and China derived from space-borne radar and radiometer data
}

\author{
Kazuaki Kawamoto ${ }^{1}$ and Kentaroh Suzuki ${ }^{2,3}$ \\ Received 15 June 2011; revised 23 January 2012; accepted 23 January 2012; published 14 March 2012.
}

[1] This study examines the transitional processes and relationships among cloud droplets, drizzle, and precipitation in single-layer water clouds over the Amazon and China by synergistically analyzing products of active CloudSat and passive Moderate Resolution Imaging Spectroradiometer sensors. Cloud droplet number concentrations $\left(N_{c}\right)$ are confirmed to generally be lower over the Amazon and higher over China, reflecting the difference in aerosol amount between these two regions at different seasons. Radar reflectivity $\left(Z_{e}\right)$ frequencies are consistent with the regional and seasonal differences in precipitation rate. Furthermore, the fractional occurrences of maximum $Z_{e}$ as a function of liquid water path (LWP) show an almost monotonic decline and increase for nonprecipitating and precipitating categories, respectively, denoting differences in the precipitation rate. The behavior of cloud parameters such as the cloud optical depth, effective particle radius, $N_{c}$, and LWP among different $Z_{e}$ categories indicates the cloud development stage and reveals regional differences in the microphysical characteristics. Finally, a vertical cloud structure is examined to illustrate that water clouds tend to become optically thinner and to produce precipitation (shifting to larger $Z_{e}$ ) through the coalescence of droplets as $N_{c}$ decreases. Regionally, precipitation over the Amazon takes place in optically thicker parts than over China.

Citation: Kawamoto, K., and K. Suzuki (2012), Microphysical transition in water clouds over the Amazon and China derived from space-borne radar and radiometer data, J. Geophys. Res., 117, D05212, doi:10.1029/2011JD016412.

\section{Introduction}

[2] Clouds play key roles in climate systems; for example, they produce precipitation and control the global energy budget via their effects on solar and infrared radiative transfer processes. It is important to understand cloud vertical structure and microphysical properties such as optical depth $\left(\tau_{c}\right)$ and effective particle radius $\left(r_{e}\right)$ for determining the effects of clouds on climate [e.g., Stephens et al., 2008].

[3] Water clouds occupy a large area of the atmosphere over both oceans and land and have been investigated more extensively than ice clouds for several reasons. One reason is that in situ measurements are easier to conduct for water clouds, which occur in the lower atmosphere, than for highaltitude ice clouds. Moreover, because water droplets are assumed to be spherical, Mie scattering theory can be applied to radiative transfer calculations. Conversely, it is difficult to determine the scattering properties of the nonspherical particles found in ice clouds.

\footnotetext{
${ }^{1}$ Graduate School of Fisheries Science and Environmental Studies, Nagasaki University, Nagasaki, Japan.

${ }^{2}$ Department of Atmospheric Science, Colorado State University, Fort Collins, Colorado, USA.

${ }^{3}$ Now at Jet Propulsion Laboratory, California Institute of Technology, Pasadena, California, USA.

Copyright 2012 by the American Geophysical Union. 0148-0227/12/2011JD016412
}

[4] Remote sensing of visible and infrared wavelengths by passive sensors has been achieved using the Advanced Very High Resolution Radiometer (AVHRR) [e.g., Han et al., 1994; Kawamoto et al., 2001] and Moderate Resolution Imaging Spectroradiometer (MODIS) [e.g., Platnick et al., 2003]. Recently, active remote sensing has also become available, such as from the CloudSat satellite. Launched in April 2006, CloudSat carries the Cloud Profiling Radar (CPR), which operates at $94 \mathrm{GHz}$. The CPR was developed to provide vertical cloud structure information on differentsized particles that could not be determined using conventional passive sensors. CloudSat is also part of the satellite constellation of passive and active sensors called the A-Train [Stephens et al., 2002]. Observations by A-Train sensors have been used to analyze the relationships among cloud droplets, drizzle, and precipitation and have provided new insights into warm cloud microphysics and its link to aerosols. Among recent studies using these data, Lebsock et al. [2008] reported aerosol effects on CloudSat radar reflectivity $\left(Z_{e}\right)$, the liquid water path (LWP), and $r_{e}$ over global oceans. Suzuki and Stephens [2008] found sixth-power and cubic relationships between $Z_{e}$ and the effective particle radius of oceanic clouds, illustrating that condensation and coagulation constituted the dominant particle growth processes at smaller and larger $Z_{e}$ values, respectively. Kubar and Hartmann [2008] collected data on tropical oceanic cloud vertical structures and quantified the relationship between cloud top height and precipitation rate. Most of 


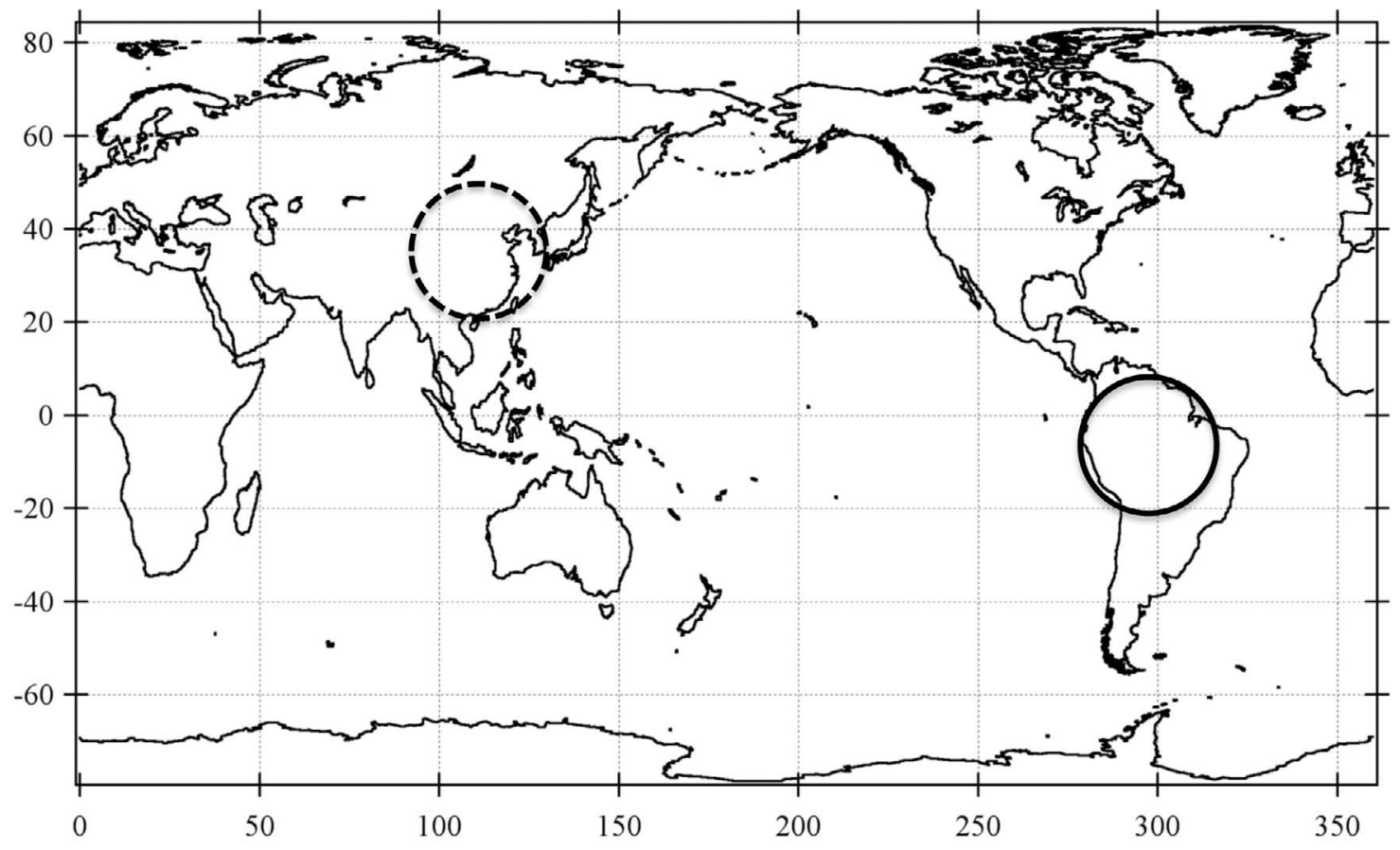

Figure 1. Map of the regions analyzed. The solid and dotted circles represent the Amazon (within $1500 \mathrm{~km}$ of $7^{\circ} \mathrm{S}$ and $60^{\circ} \mathrm{W}$ ) and China (within $1800 \mathrm{~km}$ of $35^{\circ} \mathrm{N}$ and $120^{\circ} \mathrm{E}$ ), respectively.

these previous studies, however, have been limited to oceanic clouds, partly due to their more uniform surface and the availability of microwave retrievals.

[5] On the other hand, Kawamoto [2008] compared the precipitation rate $(P)$ obtained from ground-based measurements and microphysical properties of nonprecipitating water clouds derived from passive satellite sensor data over the Amazon and China, motivated by an earlier analysis of clouds over the Amazon [Kawamoto, 2006]. He reported a positive correlation between $P$ and $r_{e}$ and a negative correlation between $P$ and columnar cloud particle number concentration as a unilateral effect of precipitation on nonprecipitating clouds, suggesting that precipitation was a factor that modifies the microphysical behaviors of nonprecipitating clouds [Kawamoto, 2008]. Although this idea is consistent with Twomey's [1977] view of aerosol scavenging by precipitation as an external forcing, it is also important to investigate the mutual relationships between cloud and precipitation.

[6] In this study, we use the novel in-cloud information provided by CloudSat to describe the transitional processes and relationships among cloud droplets, drizzle, and precipitation in water clouds instead of the unilateral effect of precipitation on water clouds. To this end, we investigate several aspects of the cloud-to-precipitation transitional processes and relationships among cloud droplets, drizzle, and precipitation inside water clouds over the Amazon, within $1500 \mathrm{~km}$ of $7^{\circ} \mathrm{S}$ and $60^{\circ} \mathrm{W}$, and over China, within $1800 \mathrm{~km}$ of $35^{\circ} \mathrm{N}$ and $120^{\circ} \mathrm{E}$ as indicated by the solid and dotted circles, respectively, in Figure 1. These regions were chosen because they have different latitudes and climatic regimes that would result in different precipitation types characterized by strong convection and frontal systems.
[7] This study is organized as follows. In section 2, we briefly describe the data sets used and the target clouds. Next, section 3 presents the main analyses of the occurrence frequencies of the cloud droplet number concentration $\left(N_{c}\right)$ and $Z_{e}$, the fractional occurrences of different $Z_{e}$ categories as a function of LWP, the behaviors of several cloud parameters among different $Z_{e}$ categories, and the changes in cloud vertical structures according to $N_{c}$. Finally, section 4 summarizes the conclusions of this study.

\section{Data Sets}

[8] We use CloudSat data collocated with MODIS products for the periods of June, July, and August (JJA) and December, January, and February (DJF) during CloudSat operation from 2006 to 2010 . The following data sets are used in this study: 2B-GEOPROF for the vertical distribution of $Z_{e}$ and cloud mask [Mace et al., 2007; Marchand et al., 2008]; 2B-TAU for visible $\tau_{c}$ of the whole cloud layer, and $r_{e}$ (with $2.15 \mu \mathrm{m}$ band) at the cloud top derived from MODIS-observed radiances [Polonsky, 2008] (available from http://www.cloudsat.cira.colostate.edu/ICD/ 2B-TAU/tau2b_icd_v1.pdf); and ECMWF-AUX for altitude and temperature profiles from the European Center for Medium-Range Weather Forecasts (ECMWF) objective archives [Partain, 2007] (available from http://www. cloudsat.cira.colostate.edu/dataICDlist.php?go=list\&path $=/$ ECMWF-AUX]).

[9] We select only single-layered and water (liquid-phase) clouds having $\tau_{c}>1$ and $r_{e}<35(\mu \mathrm{m})$ to reduce the retrieval uncertainty of the above products. The former (singlelayered) requirement is determined as follows according to the method of Haynes and Stephens [2007]. First, moving upward from the lowest layer, we examine whether layers 

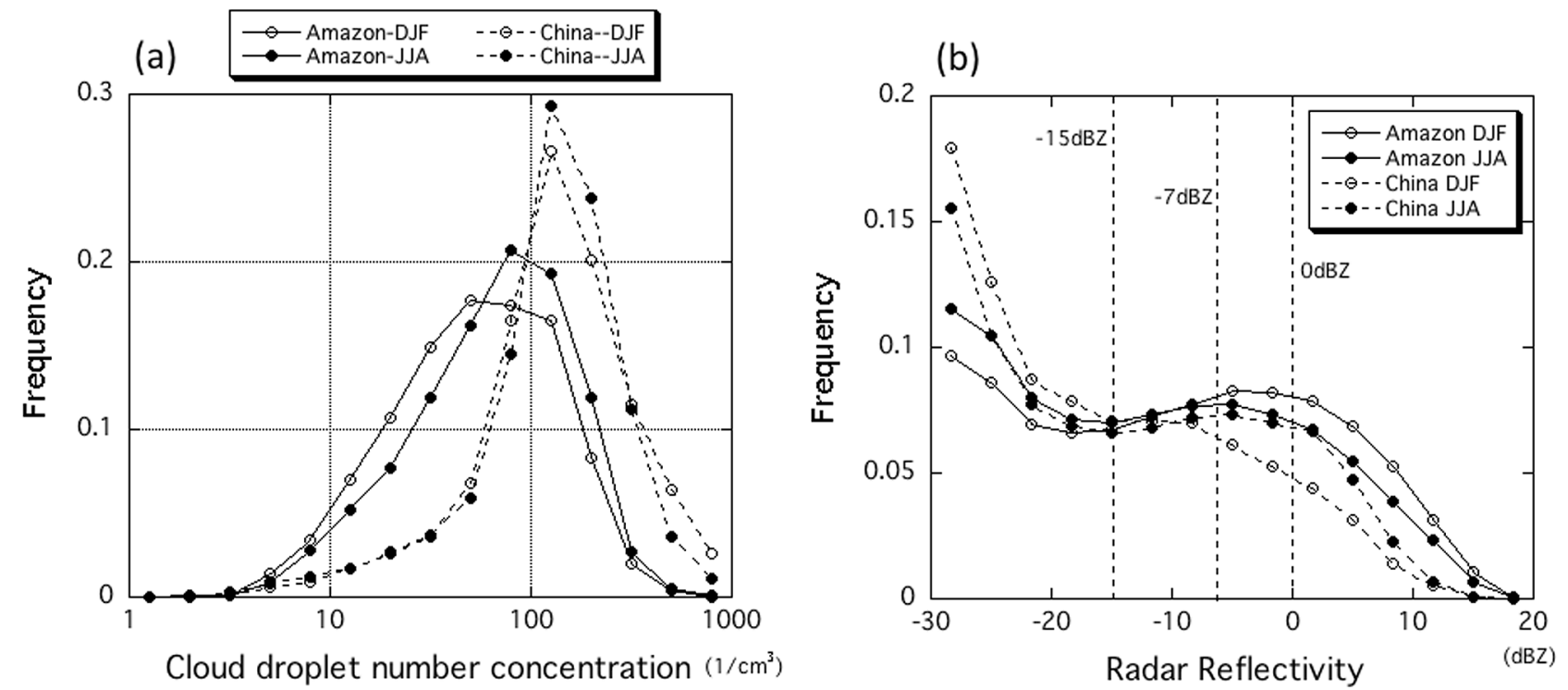

Figure 2. Frequency distributions of (a) $N_{c}$ and (b) $Z_{e}$ for all of the cloud layers over the Amazon and China for DJF and JJA. The three threshold values of $-15,-7$, and 0 (dBZ) are superimposed in Figure 2b.

meet the following three conditions: (1) the cloud mask value is between 30 and 40 , (2) $Z_{e}$ does not equal the undefined value, and (3) the height value is positive. The first height bin that satisfies all the conditions is considered the cloud base. Next, we examine the layers upward from the cloud base thus determined and identify the bins that satisfy all the conditions as the cloud layer. The layer just under the first layer not satisfying these conditions is defined as the "cloud top of the lower layer" (CTL). The same procedure is then conducted downward from the highest layer, and the first layer that satisfies all the conditions is termed the "cloud top of the higher layer" (CTH). If CTL and CTH are identical, we consider the cloud layer to be single layered. Otherwise, we conclude that the atmospheric column consists of multilayered clouds. The latter (liquid-phase) requirement is identified by the CloudSat cloud mask criterion and the echo-top temperature warmer than $273 \mathrm{~K}$.

[10] We obtain 10,157 samples for Amazon-DJF, 11,075 for Amazon-JJA, 3,919 for China-DJF, and 10,645 for China-JJA. China-DJF has a much smaller sample size because fewer water clouds are present during the midlatitude winter.

\section{Results}

\subsection{Occurrence Frequencies of $N_{c}$ and $Z_{e}$}

[11] Figure 2a shows the frequency distributions of $N_{c}$ over the Amazon and China. Values for $N_{c}$ are calculated based on the adiabatic growth model [e.g., Brenguier et al., 2000] using equation (3) for $N_{\text {eff }}$ of Kubar et al. [2009]:

$$
N_{c}=\sqrt{ } 2 B^{3} \Gamma_{\text {eff }}{ }^{1 / 2} \mathrm{LWP}^{1 / 2} / r_{e}^{3},
$$

where $B=\left(3 \pi \rho_{w} / 4\right)^{1 / 3}=0.0620$ and $\rho_{w}$ is the density of liquid water. $\Gamma_{\text {eff }}$ is the adiabatic rate of increase in the liquid water content with height, which is weakly dependent on pressure and temperature, and is taken from a diagram of Wood [2006] (available from http://www.atmos.washington. edu/ robwood/papers/chilean_plume/optical_depth_relations. pdf) (for details, see Kubar et al. [2009, and references therein]). LWP is derived from MODIS products by $5 \tau_{c} r_{e} / 9$ assuming an adiabatic cloud process [e.g., Brenguier et al., 2000].

[12] Generally, $N_{c}$ over the Amazon is found to be lower than over China. The mode values are approximately $80 \mathrm{~cm}^{-3}$ and $150 \mathrm{~cm}^{-3}$ over the Amazon and China, respectively, which are reasonable for continental clouds judged from the results of aircraft measurements [e.g., Squires, 1958; Gultepe and Isaac, 2004]. Comparing different seasons, the $N_{c}$ for Amazon-JJA is higher than that for Amazon-DJF. Over China, although the peak values of $N_{c}$ are almost the same for DJF and JJA, the frequency for China-DJF is higher for larger values $\left(>500 \mathrm{~cm}^{-3}\right)$. These regional and seasonal differences in $N_{c}$ may reflect the signature of aerosol abundance, as supported by the MODIS-retrieved aerosol optical depth (AOD) values [Remer et al., 2005], which are estimated as 0.12 and 0.11 for DJF and JJA, respectively, in the Amazon (characterized by biomass burning) and as 0.38 and 0.61 for DJF and JJA, respectively, in China (characterized by industrial and dust aerosols). These seasonal differences in $N_{c}$ and AOD could be associated with the fact that DJF is the rainy season in the Amazon and the dry season in China, whereas JJA is the dry season in the Amazon and the rainy season in China. The seasonal variation in AOD may not correspond to that in $N_{c}$ due to clear-sky bias of satellite data and incomplete matching of the observation period. Still, the characteristics of $N_{c}$ found in Figure 2a can be interpreted to reflect such regional and seasonal differences in cloud condensation nuclei processes, including those involving emissions and wet scavenging due to precipitation.

[13] To investigate the drizzle and precipitation characteristics, Figure $2 \mathrm{~b}$ shows the frequency distributions of $Z_{e}$ 
(a)

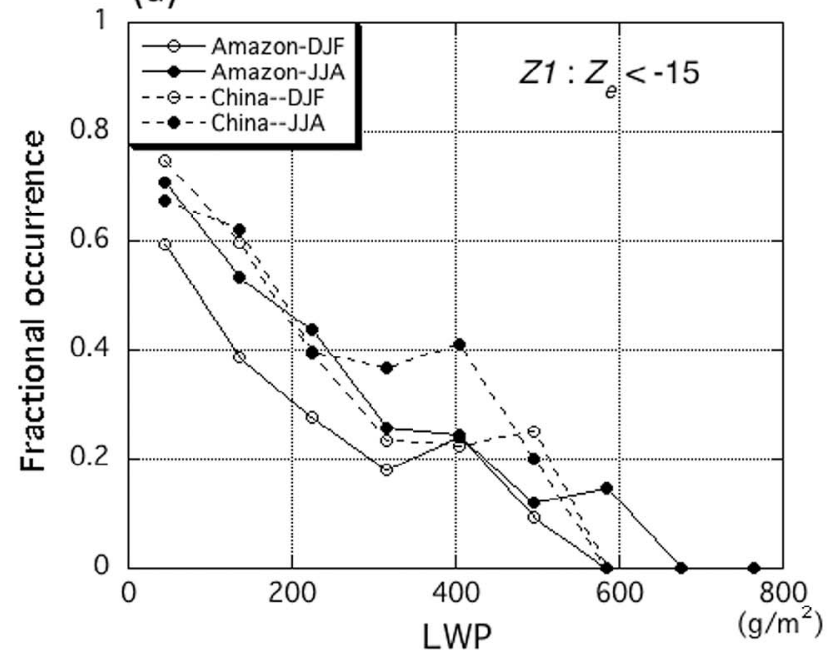

(c)

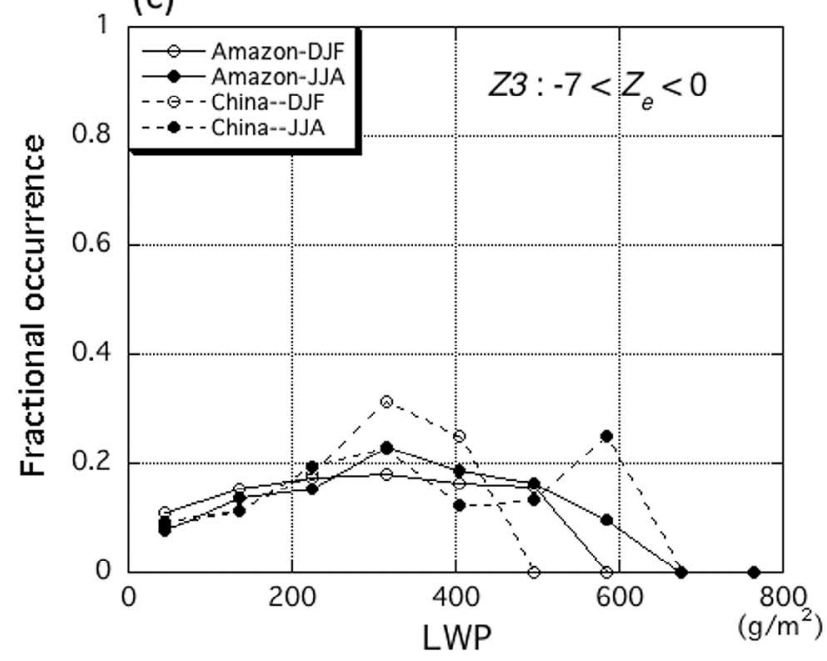

(e)

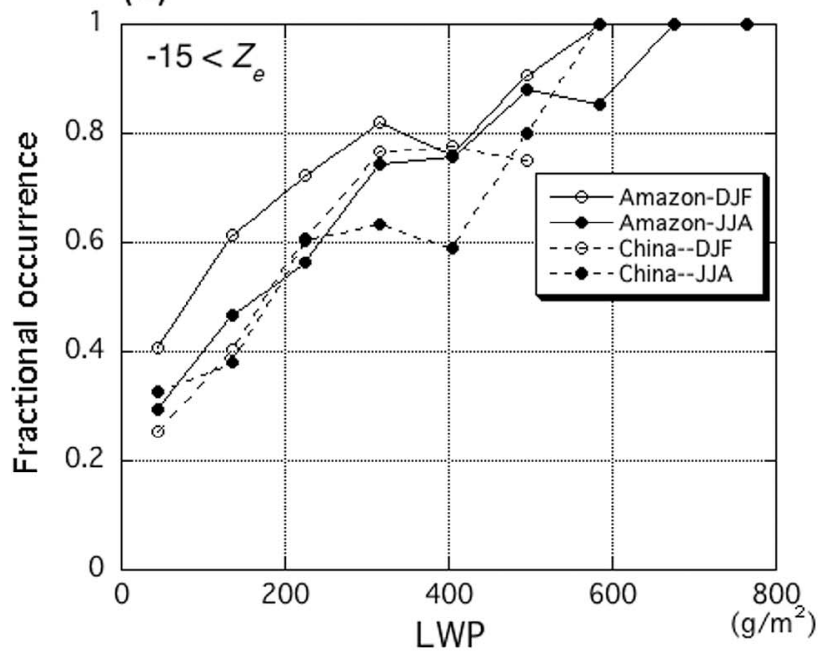

(b)

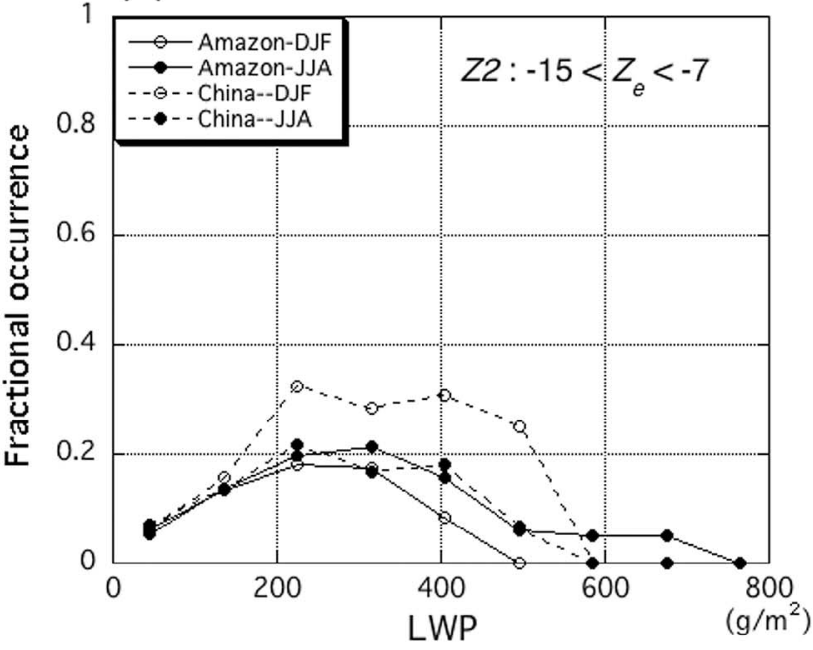

(d)

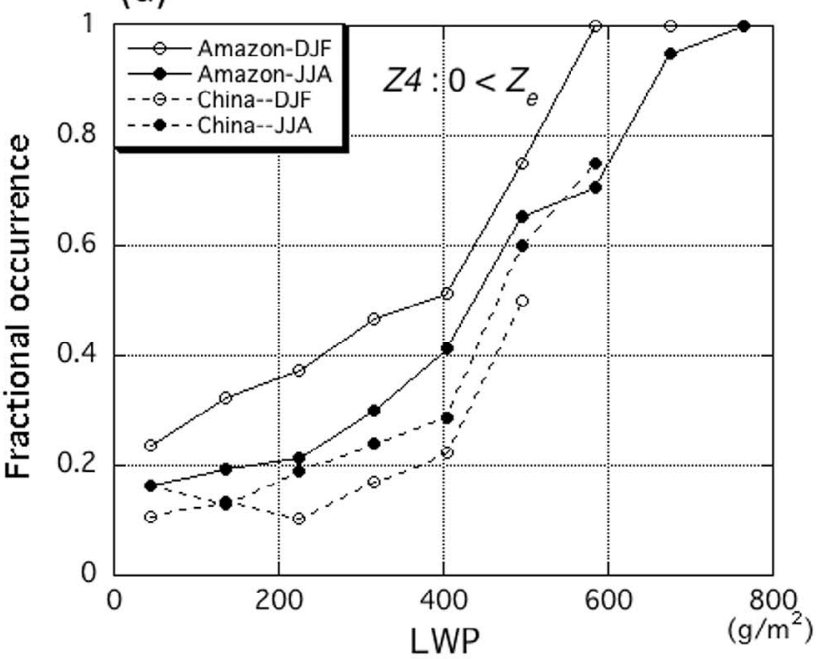

Figure 3. Fractional occurrences of the maximum $Z_{e}$ for (a) nonprecipitating $\left(Z_{e} 1, Z_{e}<-15 \mathrm{dBZ}\right.$ ), (b) drizzle $\left(Z_{e} 2,-15<Z_{e}<-7 \mathrm{dBZ}\right)$, (c) light precipitating $\left(Z_{e} 3,-7<Z_{e}<0 \mathrm{dBZ}\right)$, (d) precipitating $\left(Z_{e} 4,0 \mathrm{dBZ}<Z_{e}\right)$, and (e) summation from $Z_{e} 2$ to $Z_{e} 4$ as a function of liquid water path (LWP) over the Amazon and China for DJF and JJA. 

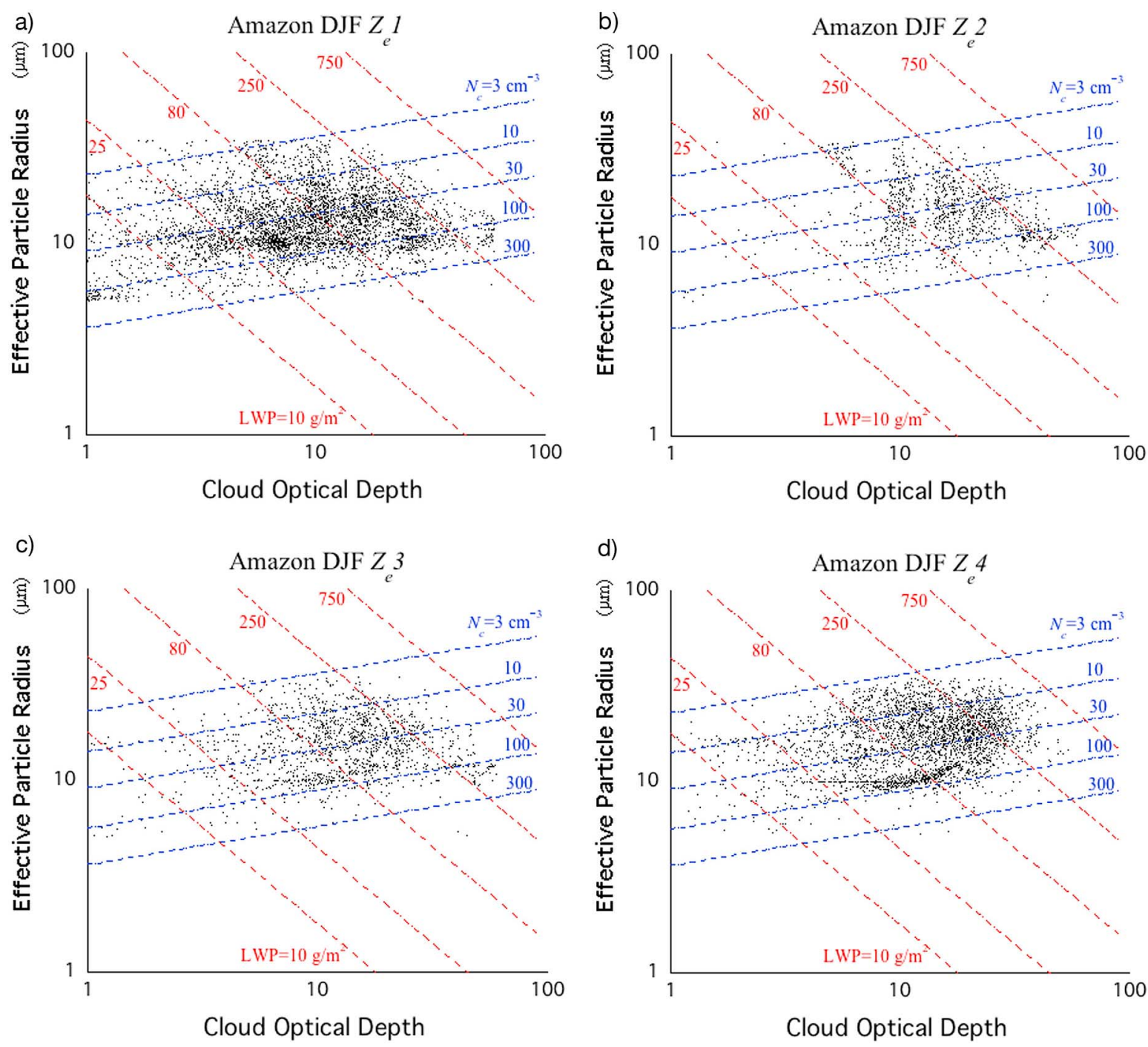

Figure 4. Scatterplots of $\tau_{c}$ and $r_{e}$ with the theoretical relationships from the adiabatic cloud model under a constant $N_{c}$ (for 3, 10, 30, 100, and $300 \mathrm{~cm}^{-3}$ ) and LWP (for 10, 25, 80, 250, and $750 \mathrm{~g} / \mathrm{m}^{2}$ ) in (a) Amazon-DJF for $Z_{e} 1\left(Z_{e}<-15 \mathrm{dBZ}\right)$, (b) Amazon-DJF for $Z_{e} 2\left(-15<Z_{e}<-7 \mathrm{dBZ}\right)$, (c) AmazonDJF for $Z_{e} 3\left(-7<Z_{e}<0 \mathrm{dBZ}\right)$, (d) Amazon-DJF for $Z_{e} 4\left(0 \mathrm{dBZ}<Z_{e}\right)$, (e) China-DJF for $Z_{e} 1$, (f) China-DJF for $Z_{e} 2$, (g) China-DJF for $Z_{e} 3$, and (h) China-DJF for $Z_{e} 4$.

for all the cloud layers over the Amazon and China. Four precipitation categories are defined according to the $Z_{e}$ value, as proposed by L'Ecuyer et al. [2009]: (1) nonprecipitating $\left(Z_{e}<-15 \mathrm{dBZ}\right)$; (2) drizzle approximately corresponding to a rain rate of less than $0.01 \mathrm{~mm} / \mathrm{h}$ (-15 dBZ $<Z_{e}<-7 \mathrm{dBZ}$ ); (3) light precipitating corresponding to a rain rate of about $0.01 \sim 0.03 \mathrm{~mm} / \mathrm{h}$ $\left(-7 \mathrm{dBZ}<Z_{e}<0 \mathrm{dBZ}\right)$; and (4) precipitating $\left(0 \mathrm{dBZ}<Z_{e}\right)$. These four categories are hereafter referred to as $Z_{e} 1, Z_{e} 2$, $Z_{e} 3$, and $Z_{e} 4$, respectively, and three threshold values, $-15 \mathrm{dBZ},-7 \mathrm{dBZ}$, and $0 \mathrm{dBZ}$ are superimposed using dotted lines in Figure 2b. Figure $2 \mathrm{~b}$ shows that the $Z_{e} 1$ frequency in the Amazon in JJA (the dry season) is larger than that in DJF (the rainy season), whereas the $Z_{e} 4$ frequency is higher in DJF than in JJA, as expected from the seasonality of precipitation. Although the differences in frequency between $Z_{e} 2$ and $Z_{e} 3$ are smaller than those between $Z_{e} 1$ and $Z_{e} 4$, we observe higher frequencies for $Z_{e} 3$ in DJF. The trends in China are similar to those in the Amazon in seasonality (reversed in month). Moreover, the frequencies are higher for $Z_{e} 3$ and $Z_{e} 4$ in the rainy season (JJA in China). Comparing the Amazon and China groups, the $Z_{e} 1$ frequencies are larger for China, with higher frequencies of about $10 \mathrm{dBZ}$ in the larger $Z_{e} 4$, implying a lower chance of no precipitation and more frequent precipitation in the Amazon. Leon et al. [2008] obtain similar bimodal features for the $Z_{e}$ frequency in marine boundary layer clouds, consistent with our results.

\subsection{Fractional Occurrence of $Z_{e}$ Versus LWP}

[14] Next, we analyze the fractional occurrence of the maximum $Z_{e}$ within the cloud layer for the four categories $\left(Z_{e} 1-Z_{e} 4\right)$ as a function of LWP, following the analysis method proposed by Lebsock et al. [2008] and L'Ecuyer et al. 


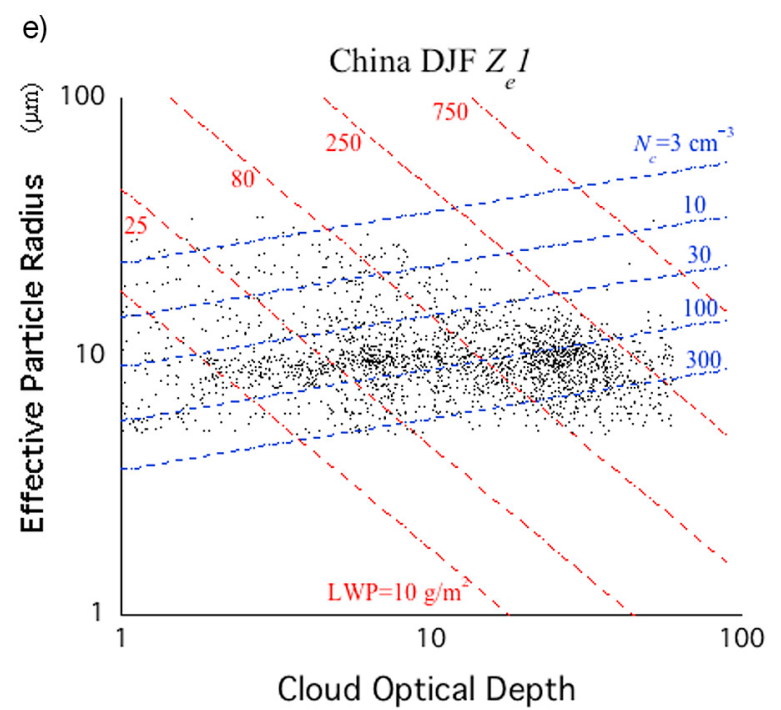

g)

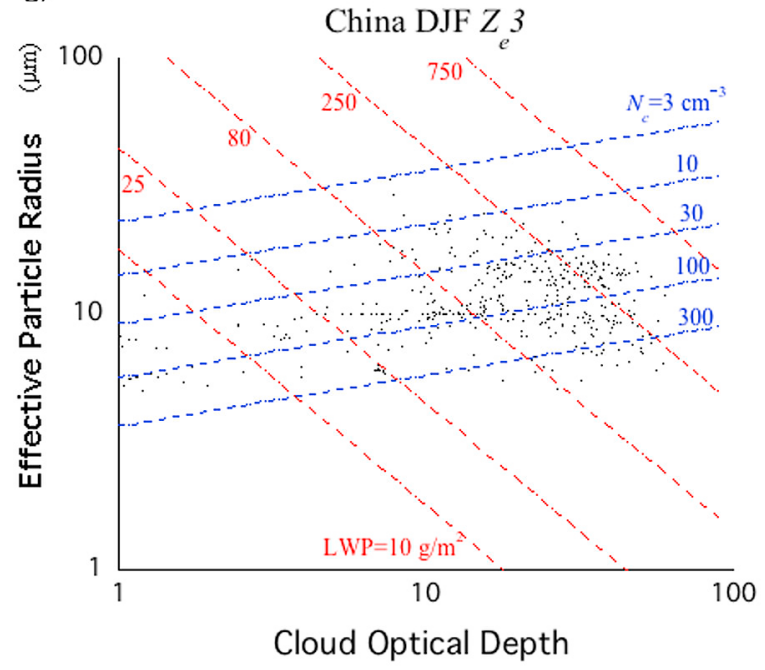

Figure 4. (continued)
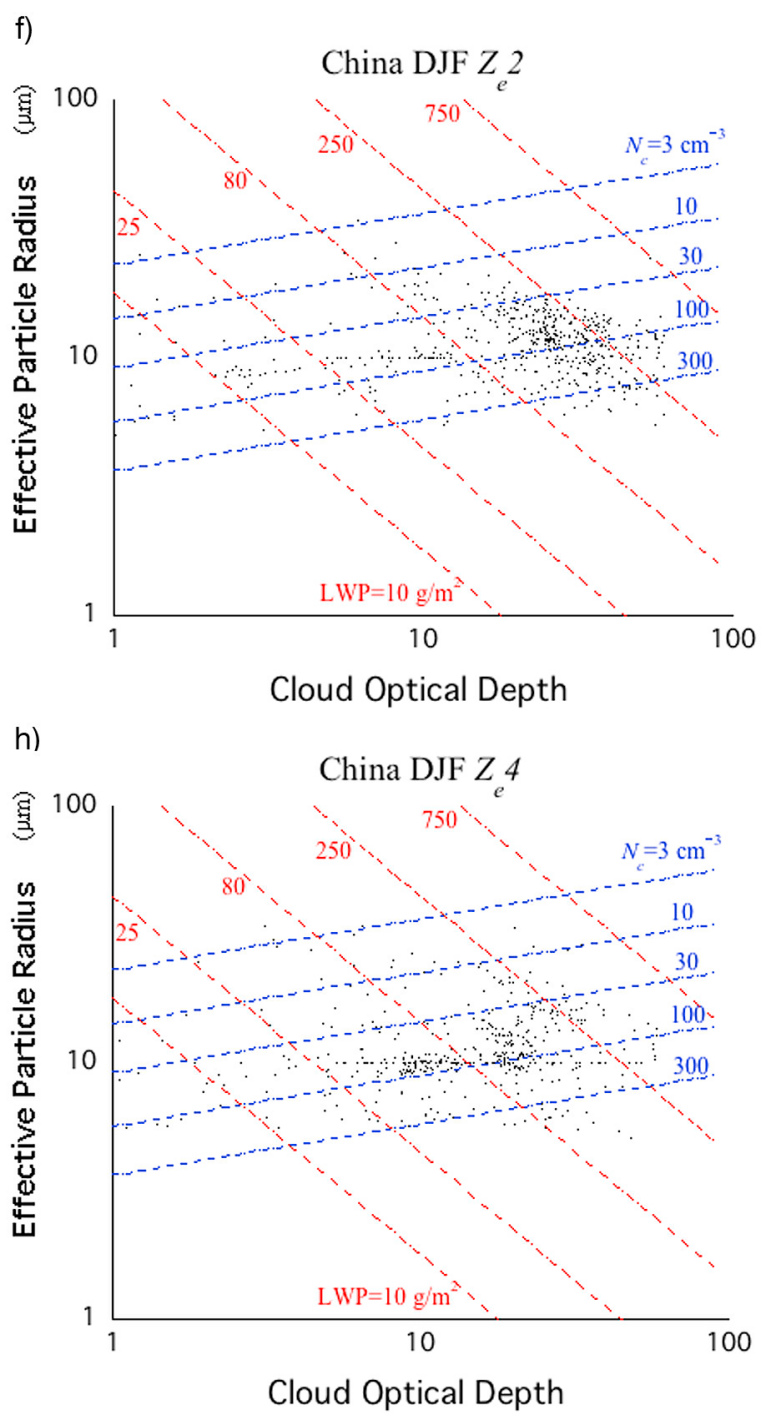

[2009], who introduced the probability of precipitation (POP) and examined its relation to LWP. They found that POP tended to increase monotonically with LWP and was significantly modified by aerosol abundance, demonstrating how cloud water tended to be converted to rainwater and how aerosols tended to influence this conversion process. Although both Lebsock et al. [2008] and L'Ecuyer et al. [2009] used LWP from microwave remote sensing in their oceanic cloud studies, we use LWP values derived from MODIS $\tau_{c}$ and $r_{e}$ because LWP retrieval using microwaves is impossible over land due to the difficulty in correcting bidirectionality. According to Horváth and Davies [2007], who compared LWP values from microwave (Tropical Rainfall Measuring Mission Microwave Imager (TMI)) and optical (MODIS and Multiangle Imaging Spectroradiometer (MISR)) estimates, both values are in quite good agreement, with an overall correlation coefficient of 0.85 and RMS difference of $25 \mathrm{~g} / \mathrm{m}^{2}$ for LWP $<300 \mathrm{~g} / \mathrm{m}^{2}$. Larger LWP values than this threshold seem to be more uncertain, although this was not quantified by Horváth and Davies [2007].

[15] Figure 3 shows the results of this analysis. Note that these panels do not show the probability distribution function (PDF) as in Figures $2 \mathrm{a}$ and $2 \mathrm{~b}$, but show fractional occurrences. In Figure 3a, an almost monotonic decline in

Table 1. Average and Standard Deviation Values of the Warm Cloud Parameters for the Four $Z_{e}$ Categories Over the Amazon and China (DJF) ${ }^{\mathrm{a}}$

\begin{tabular}{lcccc}
\hline & $\tau_{c}$ & $r_{e}(\mu \mathrm{m})$ & $N_{c}\left(\mathrm{~cm}^{-3}\right)$ & LWP $\left(\mathrm{g} / \mathrm{m}^{2}\right)$ \\
\hline Amazon $Z_{e} 1$ & $11.8(15.4)$ & $13.7(14.7)$ & $88.6(119.2)$ & $89.7(117.1)$ \\
Amazon $Z_{e} 2$ & $18.3(21.5)$ & $16.0(17.1)$ & $85.5(124.2)$ & $152.1(173.1)$ \\
Amazon $Z_{e} 3$ & $15.7(19.1)$ & $15.8(16.8)$ & $75.4(108.6)$ & $135.3(162.9)$ \\
Amazon $Z_{e} 4$ & $14.3(16.4)$ & $17.3(18.3)$ & $56.9(76.9)$ & $143.3(175.0)$ \\
China $Z_{e} 1$ & $15.9(20.5)$ & $10.3(11.0)$ & $196.5(265.8)$ & $86.4(111.8)$ \\
China $Z_{e} 2$ & $24.7(28.2)$ & $11.7(12.2)$ & $168.9(221.9)$ & $157.8(180.7)$ \\
China $Z_{e} 3$ & $21.1(25.0)$ & $11.6(12.3)$ & $170.3(232.7)$ & $139.3(168.9)$ \\
China $Z_{e} 4$ & $17.4(20.6)$ & $11.9(12.8)$ & $155.9(221.2)$ & $116.1(145.3)$ \\
\hline
\end{tabular}

${ }^{\mathrm{a}}$ Standard deviations are in parentheses. LWP, liquid water path. 

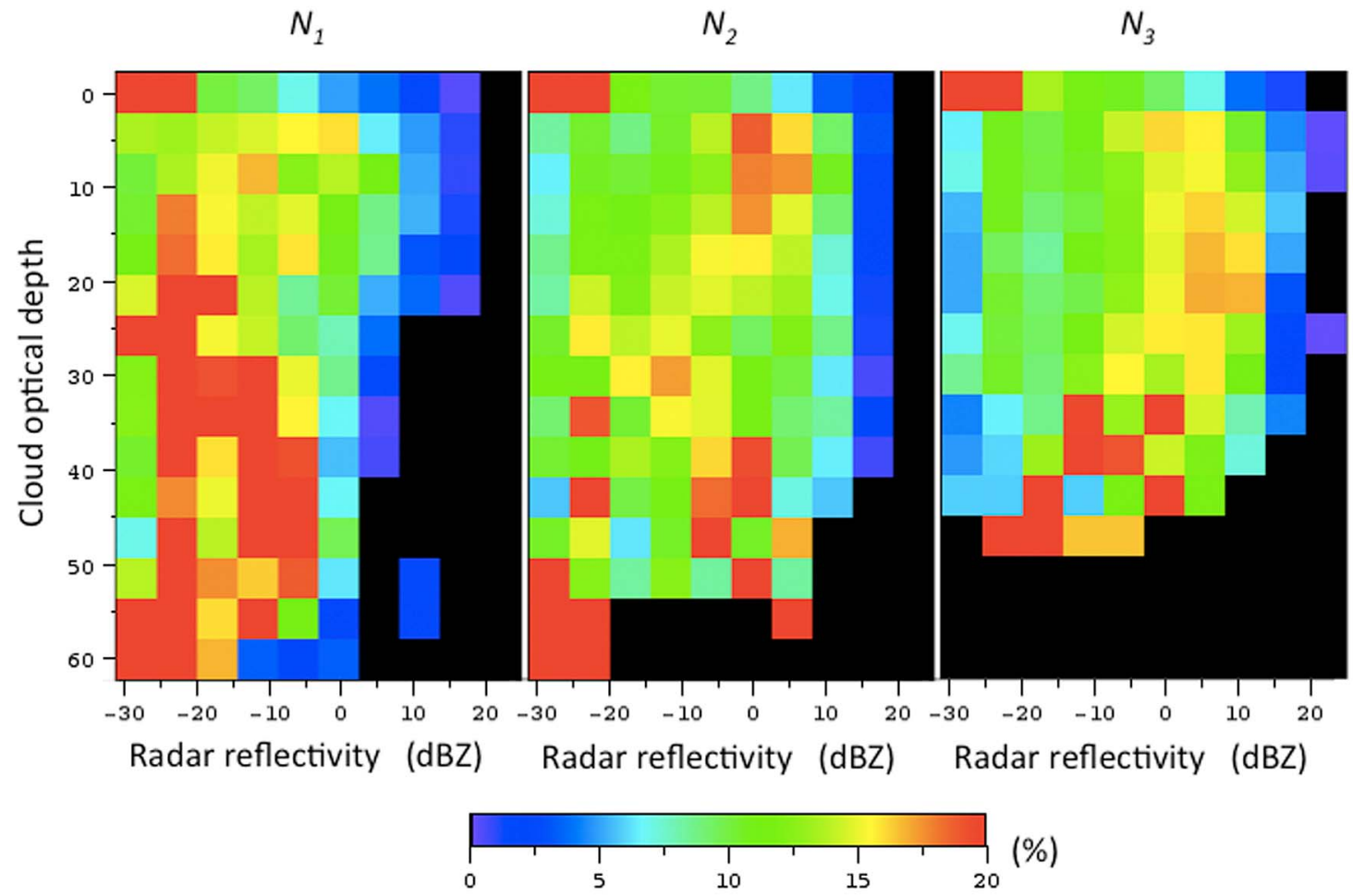

(a)

(b)

(c)

Figure 5. Contoured frequency by optical depth diagram of the (a) Amazon-DJF for $N_{1}\left(100 \mathrm{~cm}^{-3}<N_{c}\right)$, (b) Amazon-DJF for $N_{2}\left(40 \mathrm{~cm}^{-3}<N_{c}<100 \mathrm{~cm}^{-3}\right)$, (c) Amazon-DJF for $N_{3}\left(N_{c}<40 \mathrm{~cm}^{-3}\right)$, (d) AmazonJJA for $N_{1}$, (e) Amazon-JJA for $N_{2}$, (f) Amazon-JJA for $N_{3}$, (g) China-DJF for $N_{1}$, (h) China-DJF for $N_{2}$, (i) China-DJF for $N_{3}$, (j) China-JJA for $N_{1}$, (k) China-JJA for $N_{2}$, and (l) China-JJA for $N_{3}$.

the $Z_{e} 1$ category is shown with increasing LWP, indicating a greater chance of no precipitation at smaller LWP values. It is reasonable that the lowest occurrence for the nonprecipitating category is found for Amazon-DJF, when precipitation is most likely to occur among the four cases. In Figure $3 \mathrm{~b}$, most peaks in $Z_{e} 2$ occurrence are found around $\mathrm{LWP}=300 \mathrm{~g} / \mathrm{m}^{2}$. Notably, while the fractional occurrences of the $Z_{e} 3$ category (Figure $3 \mathrm{c}$ ) have a convex top similar to those of the $Z_{e} 2$ category (Figure $3 b$ ), most occurrences are shifted to larger LWP values in Figure $3 \mathrm{c}$, suggesting stronger precipitation in $Z_{e} 3$ than $Z_{e} 2$, as L'Ecuyer et al. [2009] also found for oceanic clouds. The dry season in China (DJF) has larger occurrences for less strong precipitation categories in both Figures $3 \mathrm{~b}$ and $3 \mathrm{c}$. Figure $3 \mathrm{~d}$ shows the fractional occurrence of the $Z_{e} 4$ category. In general, monotonic increases in POP with increasing LWP are observed, in contrast to Figure 3a. Moreover, Amazon-DJF, representing the rainy season, has larger occurrences than the other three cases throughout the LWP range, and the POP becomes $100 \%$ at around $600 \mathrm{~g} / \mathrm{m}^{2}$, whereas for China, the POP is less than $80 \%$. These overall tendencies are quite similar to the results of L'Ecuyer et al. [2009]. As our method of calculating POP based on the maximum $Z_{e}$ within the cloud layer differs from that of $L^{\prime} E c u y e r$ et al. [2009], who used attenuation-corrected near surface reflectivity, these two analyses cannot be compared quantitatively.
Finally, Figure 3e shows the summed fractional occurrences of $Z_{e} 2, Z_{e} 3$, and $Z_{e} 4$ (i.e., drizzle, light precipitating, and precipitating, but not nonprecipitating) as a function of LWP. Hereafter, we call this occurrence the drizzle frequency, following Kubar et al. [2009]. Most curves show the monotonic increase and asymptotic approach to unity at around $600 \mathrm{~g} / \mathrm{m}^{2}$, except the China-DJF case (dry season), which approaches 0.8 asymptotically at a smaller LWP of about $300 \mathrm{~g} / \mathrm{m}^{2}$. Kubar et al. [2009] examined a similar analysis for oceanic clouds and found a strong increase in the drizzle frequency with LWP, although for a given LWP, drizzle was more frequent in pristine regions. It is important to note that in their study, the drizzle frequency approached $100 \%$ at around $400 \mathrm{~g} / \mathrm{m}^{2}$ in the more pristine regions [see Kubar et al., 2009, Figure 11b]; in our study, the LWPs required for a nearly $100 \%$ drizzle frequency are considerably higher. This is consistent with the behavior in the more polluted regions such as the Asian coast and Gulf of Mexico in their study. Zuidema et al. [2005] examined drizzle occurrence as a function of LWP over the southeast Pacific, and their results support the above relationship. As Zuidema et al. [2005] and Kubar et al. [2009] examined oceanic clouds whose LWP covered somewhat narrower ranges than those in this study, it would be beneficial to revisit these studies to understand the difference in the development properties of clouds over ocean and land. 


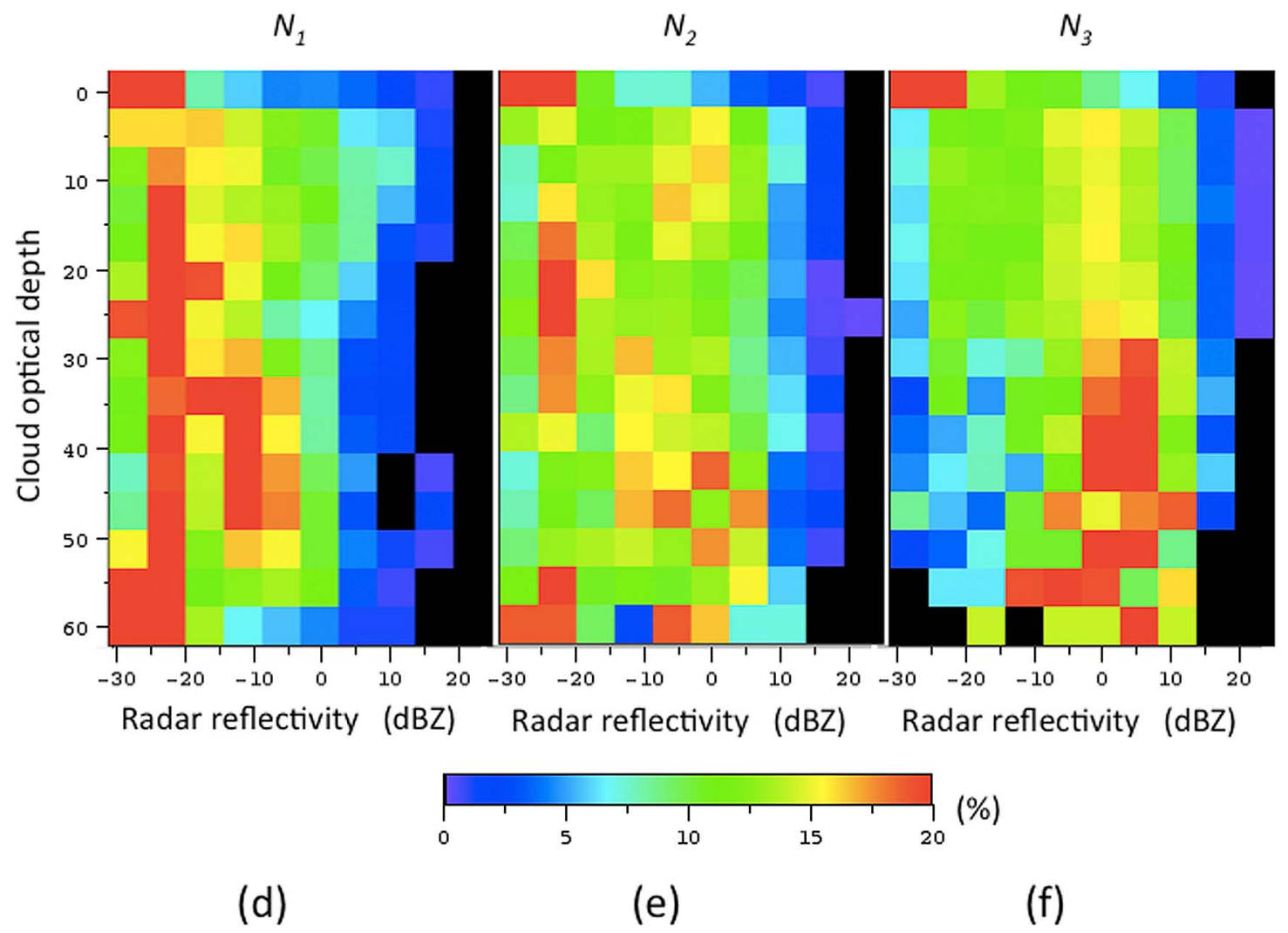

Figure 5. (continued)

\subsection{Behaviors of Cloud Parameters Among $Z_{e}$ Categories}

[16] Suzuki et al. [2010a, 2010b] proposed that the correlation statistics between $\tau_{c}$ and $r_{e}$ contained a signature of droplet growth processes, including condensation, coalescence, and evaporation [see Suzuki et al., 2010a, Figure 7] based on a spectral bin microphysics modeling study aimed at interpreting correlation statistics reported by remote sensing studies [e.g., Nakajima et al., 1991; Nakajima and Nakajima, 1995].

[17] These studies found positive and negative correlations between $\tau_{\mathrm{c}}$ and $r_{e}$. The correlation patterns were proposed to include the physical background as follows. A positive correlation reflects the following: (1) $r_{e}$ becomes larger in the growth stage, and $\tau_{c}$ gets larger via an increase in LWP and (2) $r_{e}$ becomes smaller due to evaporation, and this loss of cloud water results in a decrease in $\tau_{c}$. Conversely, a negative correlation reflects the following: (1) $r_{e}$ becomes larger through mainly the coalescence process, and the subsequent precipitation reduces $\tau_{c}$ via the loss of cloud water and (2) $r_{e}$ becomes smaller in an aerosol rich environment, and the enhanced total cross section of cloud droplets causes an increase in $\tau_{c}$ when the amount of cloud water is fixed.

[18] Here, we investigate the behaviors of cloud parameters $\left(\tau_{c}, r_{e}, N_{c}\right.$, and LWP) over the Amazon and China for different $Z_{e}$ categories to examine how they tend to relate to the different precipitation categories. As we have confirmed that the seasonal change was similar in DJF and JJA, only the DJF case is presented here. Figure 4 shows the scatterplots of $\tau_{c}$ and $r_{e}$ for the four $Z_{e}$ categories, along with the theoretical relationships from the adiabatic cloud model under a constant $N_{c}$ and LWP: Amazon-DJF $Z_{e} 1-Z_{e} 4$ (Figures $4 \mathrm{a}-4 \mathrm{~d}$ ) and China-DJF $Z_{e} 1-Z_{e} 4$ (Figures $4 \mathrm{e}-4 \mathrm{~h}$ ). The lines for specified values of $N_{c}$ and LWP apply to the growth condition via the condensation process and the vertical extent of the cloud layer, respectively [Suzuki et al., 2010a, 2010b]. Although it is difficult to identify distinct positive or negative correlation patterns in Figure 4, unlike the analyses by Nakajima and Nakajima [1995] and Suzuki et al. [2010a, 2010b], we will discuss the transitional tendencies among $Z_{e} 1-Z_{e} 4$ for both regions, together with the average and standard deviation of $\tau_{c}, r_{e}, N_{c}$, and LWP listed in Table 1. First, the average $\tau_{c}$ is the smallest for $Z_{e} 1$ and largest for $Z_{e} 2$, and it then decreases from $Z_{e} 3$ to $Z_{e} 4$ for both regions, as LWP shows similar tendencies despite the large standard deviation. For this phenomenon, we hypothesize that clouds start to store water or decay via evaporation in $Z_{e} 1$; thus, they store the maximum amount of water in $Z_{e} 2$ at the onset of drizzle and then start to precipitate, decreasing cloud water gradually from $Z_{e} 3$ to $Z_{e} 4$. As for $r_{e}$, continuous increases from $Z_{e} 1$ to $Z_{e} 4$ are recognized for both the Amazon and China due to the greatest chance of precipitation during $Z_{e} 4$, regardless of the similar $r_{e}$ values for $Z_{e} 2$ and $Z_{e} 3$. The opposite tendency to $r_{e}$ is observed for $N_{c}$. Kubar 


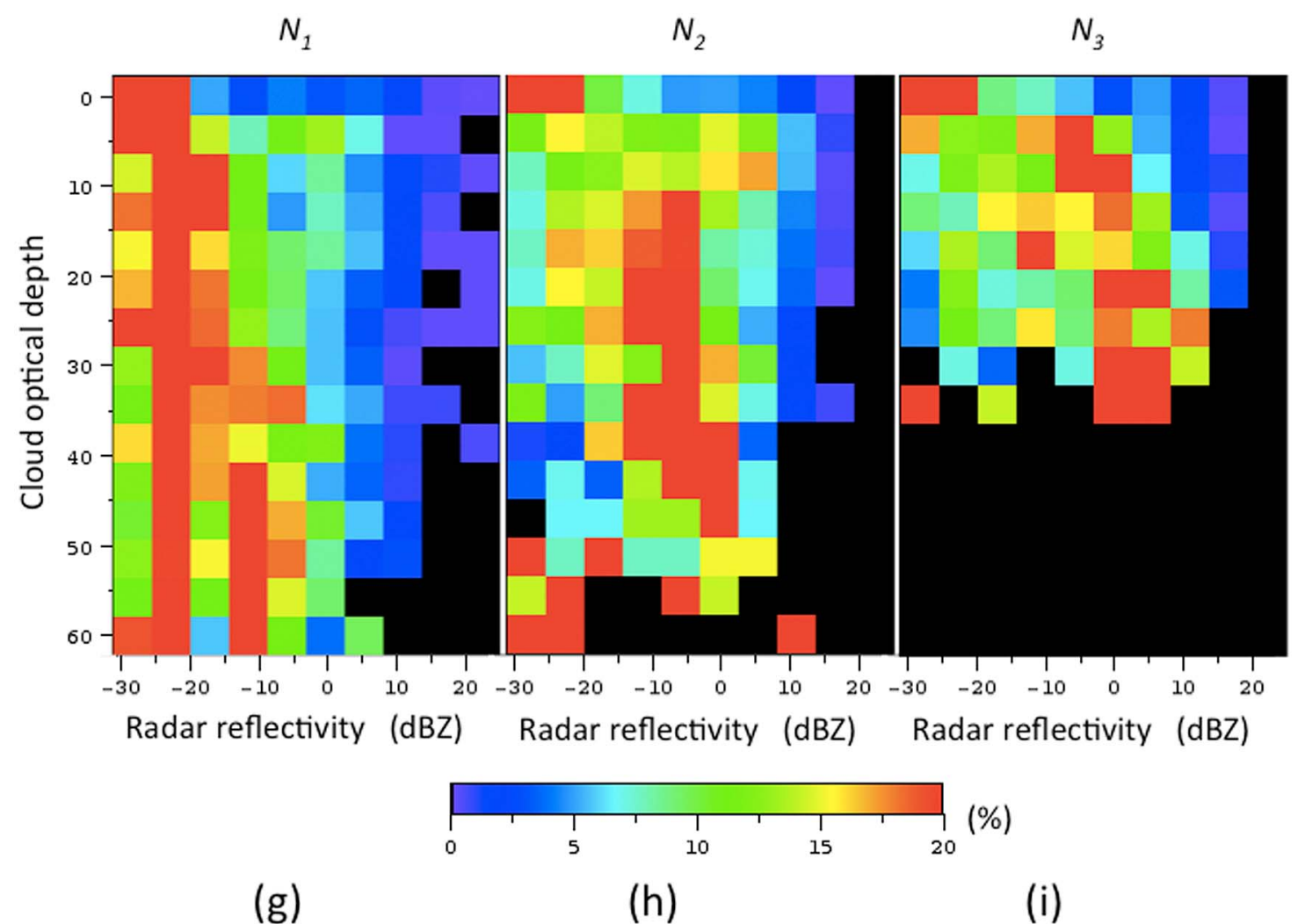

Figure 5. (continued)

et al. [2009] plotted the median LWP, $r_{e}$, and $N_{c}$ as a function of the median maximum $Z_{e}$ [see Kubar et al., 2009, Figures 9b, 10a, and 10b]. Although the tendencies for the behavior of $r_{e}$ and $N_{c}$ versus the $Z_{e}$ categories are the same in our and their analyses, the tendency with respect to LWP behavior in our analysis differs from that of Kubar et al. [2009], who reported a monotonic increase in LWP. It is interesting to consider what causes this difference in view of the land-ocean contrast. We also find that the absolute values of $\tau_{c}$ are larger over China than over the Amazon, whereas those of $r_{e}$ are larger over the Amazon than over China, consistent with the discussion of Figure $3 \mathrm{a}$ ) and the aerosol indirect effect of the first kind [Twomey, 1977]. Additionally, the range of variation of $r_{e}$ is obviously smaller for China (more flattened patterns are found in Figures $4 \mathrm{e}-4 \mathrm{~h}$ ), reflecting more AOD caused by active emission and less intensive precipitation.

\subsection{Vertical Cloud Structure}

[19] The unique vertical profile capability of CloudSat, when combined with MODIS shortwave analysis, provides new insight into microphysical processes occurring inside the cloud layer, as recently illustrated by Nakajima et al. [2010] and Suzuki et al. [2010c]. These studies proposed the use of optical depth (as the $y$ axis), instead of geometric height, to analyze $Z_{e}$ profiles (as the $x$ axis) by constructing a new diagram called the contoured frequency by optical depth diagram (CFODD), in which $Z_{e}$ profiles are rescaled as a function of in-cloud optical depth determined from the MODIS-derived $\tau_{c}$. However, Nakajima et al. [2010] adopted the in-cloud optical depth determined by the vertical profiles of $Z_{e}$, which made the $x$ and $y$ axes not completely independent. To solve this problem, Suzuki et al. [2010c] introduced an adiabatic growth model to obtain the in-cloud optical depth and found that the vertical microphysical structures in these diagrams clearly transitioned from cloud through drizzle to precipitation as a fairly monotonic function of the MODIS-derived $r_{e}$.

[20] We use the CFODD approach to investigate the vertical structures of warm clouds over the Amazon and China. Although Nakajima et al. [2010] and Suzuki et al. [2010c] classified CFODDs according to $r_{e}$, we classify CFODDs according to $N_{c}$ to more directly interpret the cloud parameter relationship to the aerosol effect. This approach helps reveal how the vertical particle growth patterns relate to $N_{c}$. For this purpose, three $N_{c}$ categories, referred to as $N_{1}, N_{2}$, and $N_{3}$, corresponding to higher, moderate, and lower cloud droplet number populations, respectively, are defined with thresholds of $40 \mathrm{~cm}^{-3}$ and $100 \mathrm{~cm}^{-3}$. Figure 5 shows the CFODDs constructed separately for the $N_{1}-N_{3}$ cases for Amazon-DJF (Figures 5a-5c), Amazon-JJA (Figures 5d-5f), China-DJF (Figures 5g-5h), and China-JJA (Figures 5j-5l).

[21] In most cases, the high-frequency parts shift to a larger $Z_{e}$ and smaller $\tau_{c}$, as $N_{c}$ decreases from $N_{1}$ to $N_{3}$. We interpret this phenomenon as follows. After the developing stage, $N_{c}$ decreases and $r_{e}$ increases through coalescence, which results in decreasing $\tau_{c}$ due to the reduction in the total cross section of particles. Moreover, the total water amount inside clouds decreases by precipitation. Evaporation can also decrease the particle size and further eliminate 


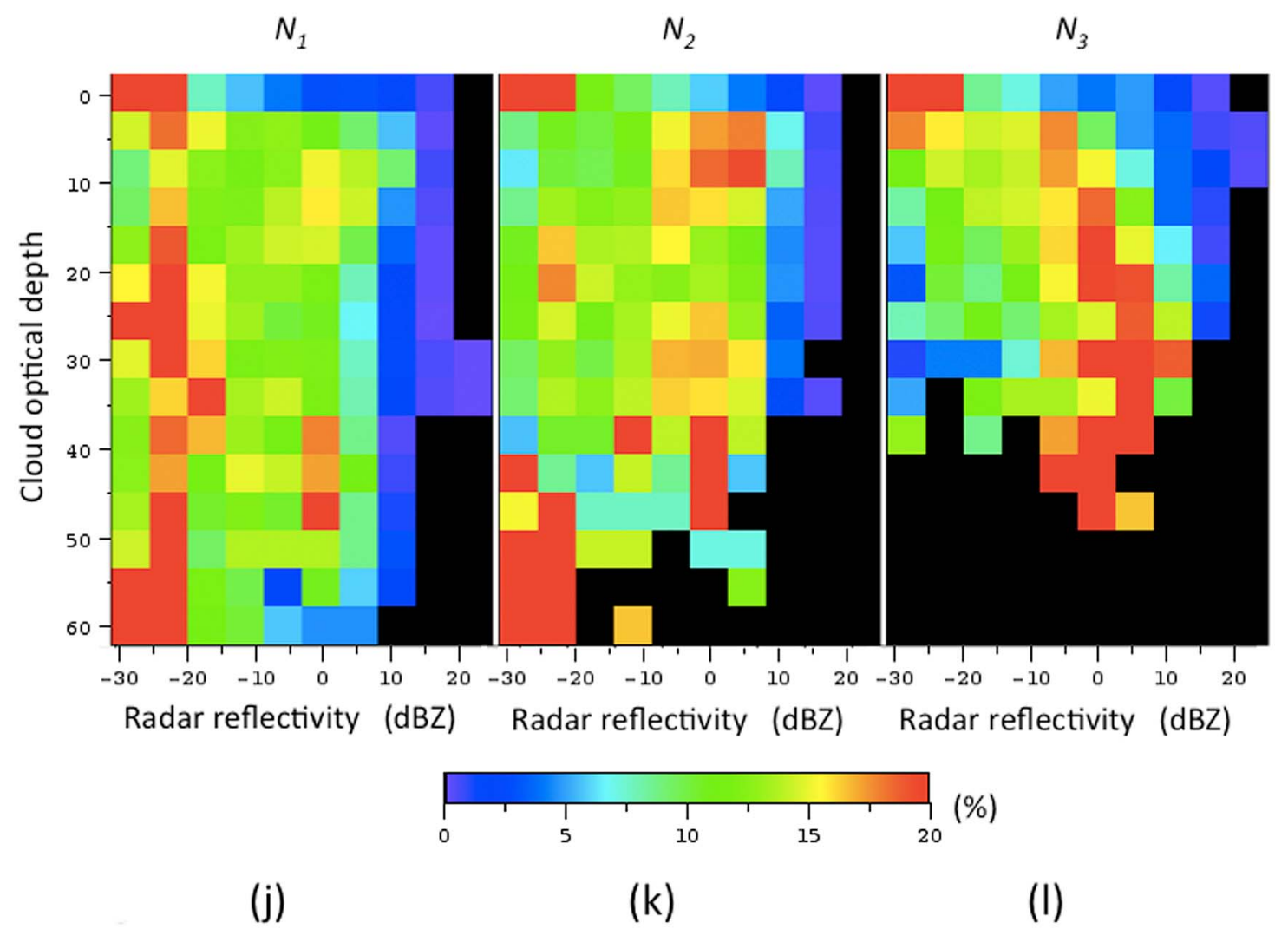

Figure 5. (continued)

particles themselves, both of which result in decreasing $\tau_{c}$ by losing the liquid water as shown in Figure 4.

[22] $N_{3}$ has a high frequency for larger $Z_{e}$, suggesting a higher occurrence of precipitation, whereas $N_{1}$ has a high frequency for smaller $Z_{e}$, denoting little precipitation. This suggests that $N_{2}$ is a transitional state between $N_{1}$ and $N_{3}$. Furthermore, the vertical extension is larger in the Amazon because of stronger convection around the tropics, especially in the $N_{3}$ cases. In China, precipitation occurs with optically thinner clouds than in the Amazon, as illustrated in Figures $5 \mathrm{i}$ and 51.

\section{Conclusions}

[23] As a natural extension of the research of Kawamoto [2008], who interpreted correlation statistics between the precipitation rate and nonprecipitating water cloud microphysics as the unilateral effect of precipitation via aerosol scavenging, this study describes and compares the transitional processes and relationships among cloud droplets, drizzle, and precipitation in single-layer water clouds over the Amazon and China, regions characterized by different climatic conditions at different latitudes, as indicated in Figure 1.

[24] We apply several analysis methods based on the synergistic use of products from the active CloudSat and passive MODIS sensors. In Figure 2, the difference in $N_{c}$ found over the two regions in DJF and JJA indicates the regional and seasonal differences in aerosol abundance, with $N_{c}$ generally lower over the Amazon and higher over China.
Additionally, the seasonal variation in $N_{c}$ is consistent with precipitation scavenging caused by the rainy/dry seasonal contrast. The $Z_{e}$ frequencies are also consistent with the annual cycle of the precipitation rate between the rainy (DJF for the Amazon and JJA for China) and dry (JJA for the Amazon and DJF for China) seasons over these two regions.

[25] Furthermore, as shown in Figure 3, the fractional occurrence of the $Z_{e}$ categories as a function of LWP shows an almost monotonic decline and increase for $Z_{e} 1$ (nonprecipitating) and $Z_{e} 4$ (precipitating) occurrences, respectively. It is also reasonable that Amazon-DJF, which has the highest precipitation probability, shows the lowest and highest probabilities in $Z_{e} 1$ and $Z_{e} 4$, respectively. Although the shapes of fractional occurrence are similar for the $Z_{e} 2$ and $Z_{e} 3$ cases, it is interesting that the $Z_{e} 3$ case (light precipitating) has peaks at larger LWP compared with the $Z_{e} 2$ case (drizzle), and that China-DJF, which has the lowest precipitation probability, has the highest values in both the $Z_{e} 2$ and $Z_{e} 3$ cases. Moreover, the drizzle frequency, defined as the summed fractional occurrence of $Z_{e} 2, Z_{e} 3$, and $Z_{e} 4$ as a function of LWP, shows a similar tendency to the result of Kubar et al. [2009], who analyzed oceanic clouds, but the difference in LWP values for $100 \%$ precipitation occurrence would be of interest to understand the differences in developmental stages of clouds over ocean and land.

[26] The behaviors of the cloud parameters among different $Z_{e}$ categories reveal regional differences in microphysical variation; for example, the absolute value and the variation range of $r_{e}$ are smaller over China as shown in Figure 4. Above all, using independent methods, it would be 
worthwhile to verify the hypothesis that clouds start to store water or decay through evaporation in $Z_{e} 1$; thus, they store the maximum amount of water in $Z_{e} 2$ at the onset of drizzle and then start to precipitate, decreasing cloud water gradually from $Z_{e} 3$ to $Z_{e} 4$, although more robust statistical analyses are needed.

[27] Finally, using CFODDs, the cloud vertical characteristics are methodically compared between the regions and the seasons as a function of $N_{c}$ in Figure 5. This approach illustrates that water clouds become optically thinner and produce precipitation (shifting to larger $Z_{e}$ ) through the coalescence of droplets as $N_{c}$ decreases. In this case, the evaporation process would also play an important role in reducing $\tau_{c}$. Regional differences between the Amazon and China in cloud vertical development can be attributed to differences in convection strength and in precipitation that occurred in optically thicker parts over the Amazon than over China. These characteristics would be closely connected to combinations of differences in dynamical and particle environments between low-latitude convective and midlatitude frontal zones. Finally, we note that synergistic use of multiple observation products and numerical modeling can aid in exploring the mechanisms of phenomena that include various development stages.

[28] Acknowledgments. K. Kawamoto was supported by the Mitsui and Co., Ltd., Environment Fund and by a Grant-in-Aid for Scientific Research on Innovative Areas. The CloudSat data products of 2B-GEOPROF, MODIS-AUX, and ECMWF-AUX were provided by the CloudSat Data Processing Center at CIRA/Colorado State University. The comments and suggestions of three anonymous reviewers greatly enhanced the quality of this paper.

\section{References}

Brenguier, J., H. Pawlowska, L. Schuller, R. Preusker, J. Fischer, and Y. Fouquart (2000), Radiative properties of boundary layer clouds: Droplet effective radius versus number concentration, J. Atmos. Sci., $57, \quad 803-821$, doi:10.1175/1520-0469(2000)057<0803:RPOBLC $>2.0$. $\mathrm{CO} ; 2$.

Gultepe, I., and G. A. Isaac (2004), Aircraft observations of cloud droplet number concentration: Implications for climate studies, Q. J. R. Meteorol. Soc., 130, 2377-2390, doi:10.1256/qj.03.120.

Han, Q., W. B. Rossow, and A. A. Lacis (1994), Near-global survey of effective droplet radii in liquid water clouds using ISCCP data, J. Clim., $7, \quad 465-497$, doi:10.1175/1520-0442(1994)007<0465:NGSOED $>2.0$. $\mathrm{CO} ; 2$.

Haynes, J. M., and G. L. Stephens (2007), Tropical oceanic cloudiness and the incidence of precipitation: Early results from CloudSat, Geophys. Res. Lett., 34, L09811, doi:10.1029/2007GL029335.

Horváth, A., and R. Davies (2007), Comparison of microwave and optical cloud water path estimates from TMI, MODIS, and MISR, J. Geophys. Res., 112, D01202, doi:10.1029/2006JD007101.

Kawamoto, K. (2006), Relationships between cloud properties and precipitation amount over the Amazon basin, Atmos. Res., 82, 239-247, doi:10.1016/j.atmosres.2005.10.007.

Kawamoto, K. (2008), Effect of precipitation on water cloud properties over China, Geophys. Res. Lett., 35, L20811, doi:10.1029/2008GL035052.

Kawamoto, K., T. Nakajima, and T. Y. Nakajima (2001), A global determination of cloud microphysics with AVHRR remote sensing, J. Clim., 14, 2054-2068, doi:10.1175/1520-0442(2001)014<2054:AGDOCM >2.0. $\mathrm{CO} ; 2$.

Kubar, T. L., and D. L. Hartmann (2008), Vertical structure of tropical oceanic convective clouds and its relation to precipitation, Geophys. Res. Lett., 35, L03804, doi:10.1029/2007GL032811.

Kubar, T. L., D. L. Hartmann, and R. Wood (2009), Understanding the importance of microphysics and macrophysics for warm rain in marine low clouds. Part I: Satellite observations, J. Atmos. Sci., 66, 2953-2972, doi:10.1175/2009JAS3071.1.

Lebsock, M. D., G. L. Stephens, and C. Kummerow (2008), Multisensor satellite observations of aerosol effects on warm clouds, J. Geophys. Res., 113, D15205, doi:10.1029/2008JD009876.
L'Ecuyer, T. S., W. Berg, J. Haynes, M. Lebsock, and T. Takemura (2009), Global observations of aerosol impacts on precipitation occurrence in warm maritime clouds, J. Geophys. Res., 114, D09211, doi:10.1029/ 2008JD011273.

Leon, D. C., Z. Wang, and D. Liu (2008), Climatology of drizzle in marine boundary layer clouds based on 1 year of data from CloudSat and CloudAerosol Lidar and Infrared Pathfinder Satellite Observations (CALIPSO), J. Geophys. Res., 113, D00A14, doi:10.1029/2008JD009835.

Mace, G. G., R. Marchand, Q. Zhang, and G. Stephens (2007), Global hydrometeor occurrence as observed by CloudSat: Initial observations from summer 2006, Geophys. Res. Lett., 34, L09808, doi:10.1029/ 2006GL029017.

Marchand, R., G. G. Mace, T. Ackerman, and G. Stephens (2008), Hydrometeor detection using CloudSat-An Earth-orbiting $94 \mathrm{GHz}$ cloud radar, J. Atmos. Oceanic Technol., 25, 519-533, doi:10.1175/ 2007JTECHA1006.1.

Nakajima, T. Y., and T. Nakajima (1995), Wide-area determination of cloud microphysical properties from NOAA AVHRR measurements for FIRE and ASTEX regions, J. Atmos. Sci., 52, 4043-4059, doi:10.1175/ 1520-0469(1995)052<4043:WADOCM $>2.0$.CO;2.

Nakajima, T., M. D. King, J. D. Spinhirne, and L. F. Radke (1991), Determination of the optical thickness and effective particle radius of clouds from reflected solar radiation measurements. Part II: Marine stratocumulus observations, J. Atmos. Sci., 48, 728-751, doi:10.1175/1520-0469 (1991)048<0728:DOTOTA >2.0.CO;2.

Nakajima, T. Y., K. Suzuki, and G. L. Stephens (2010), Droplet growth in warm water clouds observed by the A-Train. Part II: A multi-sensor view, J. Atmos. Sci., 67, 1897-1907, doi:10.1175/2010JAS3276.1.

Partain, P. (2007), Cloudsat ECMWF-AUX auxiliary data process description and interface control document, report, 10 pp., CloudSat Proj., Colo. State Univ., Fort Collins.

Platnick, S., M. D. King, S. A. Ackerman, W. P. Menzel, B. A. Baum, J. C. Riedi, and R. A. Frey (2003), The MODIS cloud products: Algorithms and examples from Terra, IEEE Trans. Geosci. Remote Sens., 41, 459-473, doi:10.1109/TGRS.2002.808301.

Polonsky, I. (2008), Level 2 cloud optical depth product process description and interface control document, report, 21 pp., CloudSat Proj., Colo. State Univ., Fort Collins.

Remer, L. A., et al. (2005), The MODIS aerosol algorithm, products and validation, J. Atmos. Sci., 62, 947-973, doi:10.1175/JAS3385.1.

Squires, P. (1958), The microstructure and colloidal stability of warm clouds. Part I: The relation between structure and stability, Tellus, 10, 256-261, doi:10.1111/j.2153-3490.1958.tb02011.x.

Stephens, G. L., et al. (2002), The CloudSat mission and the A-Train, Bull. Am. Meteorol. Soc., 83, 1771-1790, doi:10.1175/BAMS-83-12-1771.

Stephens, G. L., et al. (2008), CloudSat mission: Performance and early science after the first year of operation, J. Geophys. Res., 113, D00A18, doi:10.1029/2008JD009982.

Suzuki, K., and G. L. Stephens (2008), Global identification of warm cloud microphysical processes with combined use of A-Train observations, Geophys. Res. Lett., 35, L08805, doi:10.1029/2008GL033590.

Suzuki, K., T. Nakajima, T. Y. Nakajima, and A. P. Khain (2010a), A study of microphysical mechanisms for correlation pattern between droplet radius and optical thickness of warm clouds with a spectral bin microphysics cloud model, J. Atmos. Sci., 67, 1126-1141, doi:10.1175/ 2009JAS3283.1.

Suzuki, K., T. Nakajima, T. Y. Nakajima, and G. L. Stephens (2010b), Effect of the droplet activation process on microphysical properties of warm clouds, Environ. Res. Lett., 5, 024012, doi:10.1088/1748-9326/ $5 / 2 / 024012$

Suzuki, K., T. Y. Nakajima, and G. L. Stephens (2010c), Particle growth and drop collection efficiency of warm clouds as inferred from joint CloudSat and MODIS observations, J. Atmos. Sci., 67, 3019-3032, doi:10.1175/2010JAS3463.1.

Twomey, S. (1977), The influence of pollution on the shortwave albedo of clouds, J. Atmos. Sci., 34, 1149-1152, doi:10.1175/1520-0469(1977) 034<1149:TIOPOT $>2.0 . \mathrm{CO} ; 2$.

Wood, R. (2006), Relationships between optical depth, liquid water path, droplet concentration, and effective radius in adiabatic layer cloud, report, 3 pp., Univ. of Wash., Seattle.

Zuidema, P., E. R. Westwater, C. Fairall, and D. Hazen (2005), Ship-based liquid water path estimates in marine stratocumulus, J. Geophys. Res., 110, D20206, doi:10.1029/2005JD005833.

K. Kawamoto, Graduate School of Fisheries Science and Environmental Studies, Nagasaki University, 1-14 Bunkyo-machi, Nagasaki 852-8521, Japan. (kazukawa@nagasaki-u.ac.jp)

K. Suzuki, Jet Propulsion Laboratory, California Institute of Technology, 4800 Oak Grove Dr., MS 233-300, Pasadena, CA 91109, USA. 